\title{
Women's perception on rights during pregnancy and childbirth
}

\author{
Ibitoye O. F. ${ }^{1,2}$, Adamolekun M. M. ${ }^{3}$, Adamolekun P. A. ${ }^{4}$, Amuwa T. ${ }^{5}$
}

\author{
${ }^{1}$ Department of Health Studies, University of South Africa, ${ }^{2}$ Department of Nursing, College of Health Sciences \\ Islamic University in Uganda \\ ${ }^{3}$ Department of Maternal Neonatal and Child Health Nursing, Faculty of Nursing Sciences, University of Medical \\ Sciences, Ondo State, Nigeria \\ ${ }^{4}$ Midwifery Unit, Faculty of Nursing Sciences, University of Medical Sciences, Ondo State, Nigeria \\ ${ }^{5}$ School of Midwifery, Akure, Ondo State, Nigeria
}

Received: 13 March 2019

Accepted: 09 April 2019

*Correspondence:

Dr. Ibitoye OF,

E-mail: bisitoye04@yahoo.co.uk

Copyright: ( ) the author(s), publisher and licensee Medip Academy. This is an open-access article distributed under the terms of the Creative Commons Attribution Non-Commercial License, which permits unrestricted non-commercial use, distribution, and reproduction in any medium, provided the original work is properly cited.

\section{ABSTRACT}

Background: The Nigerian health system as a whole has been plagued by problems associated with the quality of service, including but not limited to unfriendly staff attitudes to patients, inadequate skills, decaying infrastructures, and chronic shortages of essential drugs. Approximately two-thirds of all Nigerian women deliver outside of health facilities and without the presence of medically skilled attendants. The study was carried out to assess the awareness and knowledge of women regarding their rights during pregnancy and childbirth, and to explore the extent to which women's rights were respected during pregnancy and childbirth.

Methods: This descriptive study was conducted among randomly selected 140 women at Mother and Child Hospital, Akure, Ondo state, Nigeria. Data was collected with a pretested questionnaire and was analysed using Statistical Packages for Social Sciences (SPSS) version 21.

Results: Findings revealed that majority $(76.9 \%)$ of the women had a fair knowledge of their rights in pregnancy and childbirth, with the source of knowledge majorly from their friends. Right to information, informed consent and refusal, even distribution of healthcare services, maintenance of attainable level of health regarding proper monitoring were fairly observed by the health care providers. Right of women against verbal and physical abuse, privacy, treatment with dignity and respect were least accorded to women.

Conclusions: Respective Maternity Care remains a challenge that demands policy interventions in most public health facilities to enhance positive endorsement and utilisation of maternal and health care services.

Keywords: Childbirth, Perception, Pregnancy, Rights, Women

\section{INTRODUCTION}

Despite the progress made in reducing the maternal mortality ratio in many countries, maternal mortality remains a major issue for health systems. ${ }^{1}$ South Asia and Sub-Saharan Africa, together accounts for over ninety percent of total maternal mortality. ${ }^{2}$ The Nigerian health system as a whole has been plagued by problems of service quality, including unfriendly staff attitudes to patients, inadequate skills, decaying infrastructures, and chronic shortages of essential drugs. ${ }^{3}$ In 2016, United Nations Population Fund (UNFPA) and the Department of International Development (DFID), observed that Nigeria's maternal mortality rate had risen to $10 \%$ where about 111 women die on daily basis, with Nigeria contributing about $10 \%$ of world's maternal mortality 4 . World Health Organization (WHO) likewise ranked the performance of Nigeria's healthcare system 187th among 191 United Nations member states (WHO, 2012). Approximately two-thirds of all Nigerian women deliver 
outside of health facilities and without medically skilled attendants present. ${ }^{5}$

Several schemes were put in place to eradicate or better still, minimise maternal mortality especially in Nigeria, although this were centered on ensuring that pregnancy does not become a death sentence. According to Sule and Baba, in their study on the utilisation of delivery services in Zaria, Northern Nigeria in correspondence with factors affecting choice of place of delivery, it was observed that the policy placed emphasis on strengthening maternity care at all levels of health care delivery system, by enhancing technical skills of the health care providers at all levels and strengthening referral services for emergency obstetric care, but it failed to focus on the enforcement of the rights of those pregnant and childbearing women. ${ }^{6}$

Every woman has the right to the highest attainable standard of health, which includes: the right to dignified, respectful health care throughout pregnancy and childbirth, as well as the right to be free from violence and discrimination. ${ }^{4}$ Abuse, neglect or disrespect during childbirth can amount to a violation of a woman's fundamental human rights as described in internationally adopted human rights standards and principles. ${ }^{7}$ In particular, pregnant women have a right to be equal in dignity, to be free to seek, receive and impart information, to be free from discrimination, and to enjoy the highest attainable standard of health. ${ }^{8}$

Identifying human rights norms and standards related to the full range of documented mistreatment is thus a first step towards addressing violations of human rights during facility-based childbirth, ensuring respectful and humane treatment, and developing a programme of work to improve the overall quality of maternal care. ${ }^{9}$

Despite the increasing importance of skilled birth attendance to the reduction of maternal and child mortality, it was observed that mothers utilisation of Maternal and Child Health Facilities remain relatively low. This may not be unconnected to women's complaints about health workers' attitude and lack of respective care. The mistreatment of women during facility-based childbirth raises concerns of sex and gender discrimination because it exclusively infringes upon the health and rights of women, and also limits their enjoyment of equality in access to health care. ${ }^{10}$ International human rights law recognises, too, the particular vulnerability of pregnant women, including during childbirth and for a reasonable period before and after, which may render them at greater risk of mistreatment in health care settings. ${ }^{10} \mathrm{WHO}$ recommends an insight into the weak performance of the health system in the context of the unenforced rights of the pregnant women. ${ }^{4}$ However, issues bordering on disrespect and abuse of women at childbirth in the Nigerian health system have been under-researched despite its possible importance to the reduction of Nigeria's MMR. ${ }^{11}$ This paper assess the awareness and knowledge women regarding their rights during pregnancy and childbirth and also explores the extent to which these rights were respected during pregnancy and childbirth.

\section{METHODS}

\section{Study design and setting}

This descriptive, cross-sectional study was conducted on postnatal women at Mother and Child Hospital, Akure, Nigeria. This tertiary health facility was established in 2009 as an intervention for the reduction of Maternal and Children mortality rate in Ondo State, Nigeria.

\section{Study population, sampling and sampling technique}

The study participants were postnatal women at the postnatal ward of Mother and Child Hospital, Akure. The average number of admission at the postnatal ward was 16 per day, 102 per week, 396 per month and 4754 per year (Source - Hospital records). Sample size calculated was one hundred and forty (140) based on the average number of admission into postnatal ward; margin of error of $(-5 \%)$, confidence level of $(95 \%)$ and standard deviation of (0.5). Study participants were selected randomly from the admission register at the postnatal ward; registered women who had at least 4 antenatal visits and were delivered in the hospital were used for the study. Unregistered and referred women were all exempted.

\section{Instrument and data collection}

Data was collected through a structured questionnaire adapted from related literature reviews and instruments used in previous studies. The instrument assessed socio demographic characteristics, knowledge and awareness of women regarding their rights during pregnancy and childbirth, the extent to which women's rights were respected during pregnancy and childbirth was also measured.

The instrument was pretested among 20 postnatal woman with similar characteristics at State Specialist Hospital Akure, Nigeria. All typographical errors were corrected and some unclear statements were reframed. Reliability test yielded a correlation coefficient (r) 0.75 which indicated a good internal consistency.

\section{Ethical consideration}

Ethics clearance was obtained from the Research Ethical Committee at the Mother and Child Hospital, Akure, while the consent and cooperation of the hospital's Chief Medical Director, Head of Nursing Services, and Staff of the postnatal ward were also sought. Informed consent was obtained from the respondents before data collection; right to discontinue participation at will and confidentiality of the findings were all ensured. 
Data collected between June and August 2016 by two of the researchers, all completed questionnaires and consent forms were kept in a sealed envelope only accessible to the researchers.

\section{Statistical analysis}

Data collected were analysed with the use of Statistical Package for Social Sciences (SPSS) version 21. Descriptive and inferential statistics with frequency count, percentage and cross-tabulation.

\section{RESULTS}

A total of 140 questionnaires were distributed, of which 139 were returned. The majority $(87.8 \%)$ of the participants were between the ages of 20 and 40 years; Yoruba ethnicity (81.3\%); married (94.2\%); and
Christians $(84.2 \%)$. Close to $50 \%$ of the women were civil servants, others are self-employed (39.6\%), house wives $(5.8 \%)$ and traders $(7.2 \%)$ respectively. Majority of the study participants $(73.4 \%)$ had tertiary education, normal vagina delivery $(87.8 \%)$ and has had at least two previous deliveries (64\%). Table 1 gives demographic characteristics of the respondents.

Findings on women's knowledge and awareness regarding their rights show that $76.2 \%$ of the women know about rights in pregnancy and childbirth with major source of awareness from friends (36\%) and health workers $(25.9 \%)$. There was evidence of good knowledge, more than $90 \%$ across all rights indices for women during pregnancy and childbirth in this study. Table 2 gives detailed information on women's knowledge and awareness regarding their rights during pregnancy and childbirth.

Table 1: Demographical data of the respondents.

\begin{tabular}{|c|c|c|c|c|}
\hline Age range & Frequency & Percentage & Mean & Std. Dev. \\
\hline$<20$ years & 5 & $3.6 \%$ & \multirow{3}{*}{30.6690} & \multirow{3}{*}{0.347} \\
\hline $20-40$ years & 122 & $87.8 \%$ & & \\
\hline$>40$ years & 12 & $8.6 \%$ & & \\
\hline \multicolumn{5}{|l|}{ Ethnicity } \\
\hline Yoruba & 113 & $81.3 \%$ & \multirow{3}{*}{1.21} & \multirow{3}{*}{0.458} \\
\hline Ibo & 23 & $16.5 \%$ & & \\
\hline Hausa & 3 & $2.2 \%$ & & \\
\hline \multicolumn{5}{|l|}{ Occupation } \\
\hline Civil servant & 66 & $47.5 \%$ & \multirow{4}{*}{1.71} & \multirow{4}{*}{0.848} \\
\hline Self employed & 55 & $39.6 \%$ & & \\
\hline Housewife & 8 & $5.8 \%$ & & \\
\hline Trader & 10 & $7.2 \%$ & & \\
\hline \multicolumn{5}{|l|}{ Marital status } \\
\hline Single & 1 & $0.7 \%$ & \multirow{4}{*}{2.07} & \multirow{4}{*}{0.374} \\
\hline Married & 131 & $94.2 \%$ & & \\
\hline Divorced & 3 & $2.2 \%$ & & \\
\hline Separated & 4 & $2.9 \%$ & & \\
\hline \multicolumn{5}{|l|}{ Religion } \\
\hline Christianity & 117 & $84.2 \%$ & \multirow{3}{*}{1.18} & \multirow{3}{*}{0.438} \\
\hline Islamic & 19 & $13.7 \%$ & & \\
\hline Traditional & 3 & $2.2 \%$ & & \\
\hline \multicolumn{5}{|l|}{ Educational qualification } \\
\hline Primary & 9 & $6.5 \%$ & \multirow{3}{*}{2.69} & \multirow{3}{*}{0.624} \\
\hline Secondary & 28 & $20.1 \%$ & & \\
\hline Tertiary & 102 & $73.4 \%$ & & \\
\hline \multicolumn{5}{|l|}{ Parity } \\
\hline$<2$ children & 25 & $18 \%$ & \multirow{3}{*}{2.00} & \multirow{3}{*}{0.602} \\
\hline 2-4 children & 89 & $64 \%$ & & \\
\hline$>4$ children & 25 & $18 \%$ & & \\
\hline \multicolumn{5}{|l|}{ Type of delivery } \\
\hline Vaginal & 122 & $87.8 \%$ & \multirow{4}{*}{1.25} & \multirow{4}{*}{0.733} \\
\hline Forceps & 5 & $3.6 \%$ & & \\
\hline Planned cesarean section & 6 & $4.3 \%$ & & \\
\hline Unplanned cesarean section & 6 & $4.3 \%$ & & \\
\hline
\end{tabular}


Table 2: Women's knowledge and awareness regarding their rights.

\begin{tabular}{|c|c|c|c|c|}
\hline Variables & Yes $(\%)$ & No $(\%)$ & Mean & Std. Dev. \\
\hline Knowledge regarding their right & $106(76.2 \%)$ & $33(23.7 \%)$ & 1.28 & 0.525 \\
\hline Awareness of rights as a woman during pregnancy and childbirth & $107(76.9 \%)$ & $32(23.1 \%)$ & 1.27 & 0508 \\
\hline \multicolumn{5}{|l|}{ Means of knowledge/awareness } \\
\hline A friend & 50 & $36 \%$ & \multirow{4}{*}{1.44} & \multirow{4}{*}{1.008} \\
\hline Health worker & 36 & $25.9 \%$ & & \\
\hline Mass media & 26 & $18.7 \%$ & & \\
\hline Not aware by any means & 27 & $19.4 \%$ & & \\
\hline Rights & Yes $(\%)$ & No $(\%)$ & Mean & Std. Dev. \\
\hline Right to be free from harm and ill treatment. & $135(97.1 \%)$ & $4(2.9 \%)$ & 1.03 & 0.16 \\
\hline $\begin{array}{l}\text { Right to information, informed consent and refusal, and respect for } \\
\text { her choices and preferences, including companionship during } \\
\text { maternity care. }\end{array}$ & $135(97.1 \%)$ & $4(2.9 \%)$ & 1.03 & 0.16 \\
\hline Right to privacy and confidentiality. & $127(91.4 \%)$ & $12(8.6 \%)$ & 1.09 & 0.36 \\
\hline Right to be treated with dignity and respect & $134(96.4 \%)$ & $5(3.6 \%)$ & 1.04 & 0.18 \\
\hline Right to equality, freedom from discrimination, and equitable care. & $135(97.1 \%)$ & $4(2.9 \%)$ & 1.03 & 0.16 \\
\hline Right to healthcare and to the highest attainable level of health. & $129(92.8 \%)$ & $10(7.2 \%)$ & 1.07 & 0.25 \\
\hline $\begin{array}{l}\text { Right to liberty, autonomy, self-determination, and freedom from } \\
\text { coercion. }\end{array}$ & $129(92.8 \%)$ & $10(7.2 \%)$ & 1.07 & 0.90 \\
\hline
\end{tabular}

Table 3: Extent to which women's right was respected during pregnancy and childbirth.

\begin{tabular}{|c|c|c|}
\hline Rights & Agree & Disagree \\
\hline \multicolumn{3}{|l|}{ Right to be free from harm and ill treatment } \\
\hline Providers shout at clients during childbirth & $77(55.4 \%)$ & $62(44.6 \%)$ \\
\hline Use physical force on clients during childbirth & $82(59 \%)$ & $57(41 \%)$ \\
\hline Slap clients during childbirth & $90(64.8 \%)$ & $49(35 \%)$ \\
\hline Hit or abuse clients during childbirth & $82(59 \%)$ & $57(41 \%)$ \\
\hline Provider did not separate baby without medical indication & $111(79.8 \%)$ & $28(20.2)$ \\
\hline Encourage client to take food or fluid during childbirth & $103(74.1 \%)$ & $36(24.9 \%)$ \\
\hline \multicolumn{3}{|c|}{$\begin{array}{l}\text { Right to information, informed consent and refusal, and respect for her choices and preferences, including } \\
\text { companionship during maternity care. }\end{array}$} \\
\hline Explained procedures to the clients prior to actions & $108(77.7 \%)$ & $31(22.3 \%)$ \\
\hline Encouraged clients to ask questions & $110(79.2 \%)$ & $29(20.8 \%)$ \\
\hline Explain what will happen during labour to patient & $110(79.2 \%)$ & $29(20.8 \%)$ \\
\hline Provide adequate and accurate information on progress and findings to the client & $104(74.8 \%)$ & $35(25.2 \%)$ \\
\hline Encouraged women to have a friend or relative with them for support & $73(52.5 \%)$ & $66(47.5 \%)$ \\
\hline \multicolumn{3}{|l|}{ Right to privacy and confidentiality } \\
\hline Use of drapes to preserve women's right to privacy & $66(47.5 \%)$ & $73(52.5 \%)$ \\
\hline Ensure confidentiality of all information gotten from client & $98(70.5 \%)$ & $41(29.5 \%)$ \\
\hline \multicolumn{3}{|l|}{ Right to be treated with dignity and respect } \\
\hline Treat women with dignity and respect & $51(36.7 \%)$ & $88(63.3 \%)$ \\
\hline Respectful greeting by their provider & $81(58.3 \%)$ & $58(41.9 \%)$ \\
\hline \multicolumn{3}{|l|}{ Right to equality, freedom from discrimination, and equitable care. } \\
\hline Ensure even distribution of healthcare services and avoid preferential treatment & $86(61.9 \%)$ & $53(38.1 \%)$ \\
\hline Supports in friendly way during labour & $79(56.8 \%)$ & $60(43.2 \%)$ \\
\hline \multicolumn{3}{|l|}{ Right to healthcare and to the highest attainable level of health. } \\
\hline Monitor and care for client frequently during pregnancy and childbirth & $113(81.3 \%)$ & $26(18.7 \%)$ \\
\hline Avoid delay in identifying client's need and in decision-making & $108(77.7 \%)$ & $31(22.3 \%)$ \\
\hline Promotes women's right to choose evidence based and client-focused care practices. & $108(77.7 \%)$ & $31(22.3 \%)$ \\
\hline \multicolumn{3}{|l|}{ Right to liberty, autonomy, self-determination, and freedom from coercion } \\
\hline Ask client if she has any question & $86(61.9 \%)$ & $53(38.1 \%)$ \\
\hline $\begin{array}{l}\text { Allow client to verbalize their fears and their choices respected during pregnancy and } \\
\text { childbirth }\end{array}$ & $92(66.2 \%)$ & $47(33.8 \%)$ \\
\hline Explain procedure before proceeding & $94(67.6 \%)$ & $45(32.4 \%)$ \\
\hline
\end{tabular}


Table 3 on the extent to which women's right were respected during pregnancy and childbirth indicates that largely $70 \%$ and above of the women in this study expressed confirmation respect of their rights against harm and ill treatment especially in the areas of feeding and being kept together with their newborn. However, rights against verbal and physical abuse were fairly above average.

Right to information, informed consent and refusal were affirmed to be respected by majority of women while respect for their choices and preferences including companionship during child birth was only observed by $73(52.5 \%)$ of the participants. Women's right to privacy recorded low respect $66(47.5 \%)$ while confidentiality of information had high scores $98(70.5 \%)$. The treatment of women with dignity and respect was very low 51 $(36.7 \%)$. However, majority of the women reported being greeted with respect by their providers.

More than $61.9 \%$ of the study participants expressed even distribution of healthcare services without preferential treatment while friendly support during labour was just on the average $(56.8 \%)$. Higher percentage of the women agreed to highest maintenance of attainable level of health regarding proper monitoring, identification of individual need, decision making, evidence-based and client-focused care practices. Likewise all indices under the women's right to liberty, autonomy, selfdetermination, and freedom from coercion were observed in this study.

\section{DISCUSSION}

This study sets to establish women's awareness and knowledge of their rights during pregnancy and childbirth as well as the extent to which these rights are respected during pregnancy and childbirth. The study shows that majority of the study participants have fair knowledge of their rights in pregnancy and childbirth, similarly, relatively high level of knowledge of women rights during pregnancy and child birth in Rodrigues, Soraya et al study. ${ }^{12}$ Evidence of good knowledge across all rights indices during pregnancy and childbirth was also observed in this study. Report of women knowledge in previous study indicated good knowledge of right to receive information on attendance at prenatal care, delivery and post-partum, right to equality, freedom from discrimination, and equitable care, right to healthcare and to the highest attainable level of health, right to liberty, autonomy, self-discrimination, and freedom from coercion among others. ${ }^{12}$ The correlation of these study findings may imply good knowledge rights among women of reproductive ages.

Issues associated with maternity care which shows respect for the rights of women remain a major concern across Africa. Conformity with women's right against verbal and physical abuse was just a bit above average in this study. Likewise about 18 cases of harmful treatment during childbirth was observed in five East and Southern African countries, while two incidents of slapping or hitting the client usually in connection to the client not complying with provider's orders were also recorded in another study. ${ }^{13}$

Right to information, informed consent and refusal obliged to women in this study and other previous studies. ${ }^{13,14}$ However, respect for women choices and preferences especially companionship was low in correlation similar previous reports. ${ }^{14-16}$ Equally, other studies rated the attitude of midwives regarding therapeutic presence and companionship as being poor. ${ }^{17,19}$

The treatment of women with dignity and respect was rated very low despite women's report of being greeted with respect by their provider. In agreement with this study's finding, respectful greeting by their provider was observed by larger percentage of women in the study conducted by Rosen, et al. ${ }^{13}$ Inversely, Amroussia, Hernandez et al, revealed discriminatory practices among women during postnatal healthcare services; participants in their study described how they felt judged by the health workers who openly blamed them for having a baby outside of marriage. ${ }^{19}$

Even distribution of healthcare, highest maintenance of attainable level of health regarding proper monitoring, identification of individual need, decision making, and evidence based and client-focused care practices were rated fairly high by participants in this study. But on the contrary, observers in other studies revealed denial and/or delays in receiving adequate management for prevention of postpartum hemorrhage or augmentation of labour due to lack of finances. Participants mentioned that they felt neglected, ignored, and disrespected by the maternal healthcare providers who, for example, never asked for their consent before performing medical procedures. ${ }^{13}$ Findings from a new revealed that the participants often complained about suffering from hunger, cold and risking post-delivery complications as a result of the neglect. Pregnancy and childbirth experiences have the potentials to strengthen self-confidence or on the contrary, it can mean failure. These experiences are not limited to the birth situations but radiate to other dimensions of women's life. ${ }^{19}$

\section{CONCLUSION}

International human rights law recognises the particular vulnerability of pregnant women especially during childbirth, and for a reasonable period before and after, which may render them at greater risk of mistreatment in health care settings.

Identifying women's rights norms and standards related to the full range of documented mistreatment is thus, a first step towards addressing violations of human rights during facility-based childbirth, ensuring respectful and 
humane treatment, and developing a programme of work to improve the overall quality of maternal care.

Funding: No funding sources

Conflict of interest: None declared

Ethical approval: The study was approved by the Research Ethical Committee at the Mother and Child Hospital, Akure, Ondo State Nigeria, Nigeria

\section{REFERENCES}

1. Alkema, Leontine, Doris C, Daniel H, Sanqian Z, Ann-Beth $\mathrm{M}$, et al. Global, regional, and national levels and trends in maternal mortality between 1990 and 2015, with scenario-based projections to 2030: a systematic analysis by the UN Maternal Mortality Estimation Inter-Agency Group. The Lancet.2016;387(10017):462-74.

2. Van den Broek NR, Falconer AD. Maternal mortality and Millennium Development Goal 5. British Med Bullet. 2011;99:1.

3. Lanre-Abass, Bolatito A. Poverty and maternal mortality in Nigeria: towards a more viable ethics of modern medical practice. Int $\mathrm{J}$ Equity Health. 2008;7(1): 11 .

4. World Health Organization. WHO country cooperation strategy 2014-2019: Nigeria.

5. World Health Organization. WHO statement: the prevention and elimination of disrespect and abuse during facility-based childbirth. Geneva: World Health Organization; 2012.

6. Sule T, Baba L. Utilisation of delivery services in Zaria, northern Nigeria: factors affecting choice of place of delivery. East African J Pub Health. 2012;9(2):80-4.

7. Alliance WR. Respectful maternity care: the universal rights of childbearing women. Washington (District of Columbia): White Ribbon Alliance; 2011.

8. United Nations General Assembly. The future we want. Resolution. 2012;66:288.

9. Mojekwu, Nnamdi J, Ibekwe U. Maternal mortality in Nigeria: Examination of intervention methods. Int J Human Social Sci. 2012;2(20):135-49.

10. Grover, Anand, Citro B. India: access to affordable drugs and the right to health. Lancet. 2011;377(9770):976-7.
11. Okafor, Innocent I, Ugwu EO, Obi SN. Disrespect and abuse during facility-based childbirth in a low-income country. Int $\mathbf{J}$ Gynecol Obstet. 2015;128(2):110-3.

12. Rodrigues, César R, Soraya E, Torquato JA, Davim RMB, Oliveira LFM, Alves ESRC, Nóbrega MF. Perception of women on their rights in pregnancy and childbirth. J Nur UFPE/Revista de Enfermagem UFPE. 2016;10:5.

13. Rosen, Heather E, Lynam PF, Catherine C, Veronica $\mathrm{R}$, Jim R, et al. Direct observation of respectful maternity care in five countries: a cross-sectional study of health facilities in East and Southern Africa. BMC Pregnancy Childbirth. 2015;15(1):306.

14. Ibitoye, Fatimo O. Developing a culturally congruent continuous labour support framework for women in South-West Nigeria. PhD diss., University of the Western Cape. 2017.

15. Daniel, Grace, Modupe Oyetunde, Eleri G. Mothers' validation of midwives care in the management of labour pain in Plateau State, Nigeria; 2015.

16. Morhason-Bello IO, Olayemi O, Ojengbede OA, Adedokun OB, Okuyemi OO, Orji B. Attitude and preferences of Nigerian antenatal women to social support during labour. J Bio Sci. 2008;40(4):553-62.

17. Onasoga OA, Opiah MM, Osaji TA, Iwolisi A. Perceived effects of midwives attitude towards women in labour in Bayelsa State, Nigeria. Appl Sci Res. 2012;4(2):960-4.

18. Oluyemisi, Adeyemo F, Oyadiran GO, Ijedimma MO, Akinlabi BO, Adewale AJ. Perception of pregnant women towards midwives: attitude and practice during child delivery in health institutions in Ogbomoso, South-West, Nigeria. Epidemiol Biostat Pub Health. 2014;11:2.

19. Amroussia, Nada, Alison H, Carmen VC, Isabel G. Is the doctor God to punish me?! An intersectional examination of disrespectful and abusive care during childbirth against single mothers in Tunisia. Reprod Heal. 2017;14(1):32.

Cite this article as: Ibitoye OF, Adamolekun MM, Adamolekun PA, Amuwa T. Women's perception on rights during pregnancy and childbirth. Int J Reprod Contracept Obstet Gynecol 2019;8:2652-7. 